\title{
Study of Early and Reliable Fire Detection in Air-Conditioned Rooms
}

\author{
KOHYU SATOH \\ Fire Research Institute of Japan \\ Mitaka, Tokyo 181, Japan
}

\begin{abstract}
This study describes the early and reliable fire detection in air-conditioned rooms. It is important to detect fires in their earlier stages as possible, but young fires' weak signals reaching fire detectors are generally indistinguishable from those by non-fire sources. Moreover, the flows due to air-conditioners equipped in recent buildings highly affect the fire gases in rooms, which increases the difficulty in early and reliable fire detection.

The objective of this study is to investigate the interactions between fire gases and air-conditioning flow in rooms in relation to the effectiveness of multi-sensor fire detectors including the carbon monoxide sensor. First described is the experimental results of fire gas flow in rooms with and without air-conditioner. And next made are numerical studies to visually examine the flow patterns of fire gases in air-conditioned rooms.

It has been found that air-conditioners equipped in rooms greatly affect the flow patterns in rooms and cause the dilution of not only the smoke and fire gases but also the cigarette smoke and bath steam which often cause false alarms. Therefore the recognition of fires or non-fires in the air-conditioned rooms must be made in lower sensor signal levels than the traditional ones, so multi-sensor fire detectors including the carbon monoxide sensor are highly effective to detect fires earlier and reliably in air-conditioned rooms.
\end{abstract}

KEY WORDS : fire detection, false fire alarm, smoke detector, carbon monoxide, intelligent fire detector, multi-sensor, air-conditioning, fire simulation, field model

\section{INTRODUCTION}

It is important to detect fires as early as possible during their undeveloped stages. The early detection of fires is however not always easy since young fires' weak signals reaching 
detectors are generally indistinguishable from those due to miscellaneous non-fire sources such as bath steam and cigarette smoke.

There happen numerous false fire alarms in many building in the world, so in some cases sensitivities of fire detectors are intentionally reduced and in other cases fire alarms are mechanically stopped for a while, which causes the delay or missing of fire detection. Thus early and reliable intelligent fire detectors are needed ${ }^{14}$.

In addition, there exists another problem in fire detection in rooms. Recent buildings are generally equipped with air-conditioners which cause the dilution of smoke and fire gases.

As a result the delay or missing of fire detection may increase in the air-conditioned rooms.

However most fire detection studies have been related to those in calm rooms without air-conditioning. Other few studies ${ }^{2)}$ on fire detections in air-conditioned rooms were made in very special space such as computer rooms or clean-rooms in LSI factory, where extremely high-sensitive smoke detectors are installed in the air-conditioning suction ducts.

On the other hand, extremely high-sensitive smoke detectors must produce frequent false alarms in ordinary spaces such as offices, residences and hotel rooms. Therefore early and reliable fire detectors available in ordinary air-conditioned rooms are required at present.

Hopeful is the fire detector consisted of multi-sensors including the sensor of carbon monoxide which is popularly produced in room fires. Recently the electrochemical carbon monoxide sensor is in rapid progress as well as the semi-conductor one. The multi-sensor fire detector developed by the author et al. ${ }^{3,4}$ needs the recognition logic, called the Fuzzy Expert System, to judge fires or non-fires. The objective of this study is to investigate the flow behavior of smoke and carbon monoxide gas within the air-conditioning flow in such an ordinary space as hotel rooms, in order to assist the construction of recognition logic.

Described are the experimental results of fire gas flow in the room with and without airconditioning and numerical studies made to visually investigate the flow patterns of fire gas and cigarette smoke in air-conditioned rooms.

\section{EXPERIMENTS OF SMOKE AND FIRE GAS FLOW}

\section{Experimental setup}

Measurements of smoke and gas flow were performed in the room with dimensions of $4.5 \mathrm{X}$ $4.5 \times 2.45 \mathrm{~m}$ (height) as shown in Figure 1. The warm or cool air was supplied from an inlet $(60 \times 10 \mathrm{~cm})$ located at an upper part of the wall. The room air was extracted from an outlet $(120 \times 2 \mathrm{~cm})$ near the floor. The air-conditioner equipped in the room blew out warm or cool air

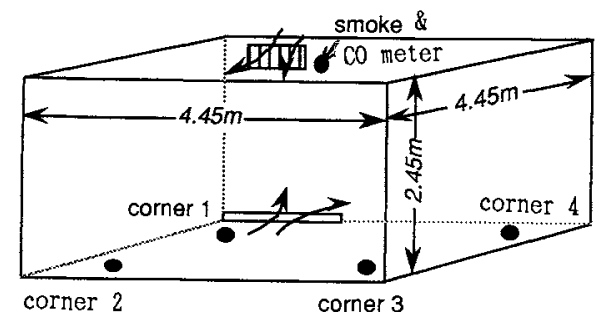

FIGURE 1 Schematics of experimental room equipped with a warm and cool air-conditioner. with two kinds of comparatively weak speed ( $\mathrm{Vo}$ ) of about 1.0 or $2.5 \mathrm{~m} / \mathrm{sec}$. The initial room temperature was about $22 \pm 2^{\circ} \mathrm{C}$. The temperatures of cool and warm air were about 17 and $27^{\circ} \mathrm{C}$, respectively. The walls and ceiling of the room were papered on the fire-proof plaster board and the floor was carpeted to simulate a hotel guest room. 


\section{Smoke and Fire Gas Measurement}

A smoke detector, a carbon monoxide (CO) meter and a thermocouple were placed in the center of the ceiling as shown in Figure 1 . The sensors' signals were measured by a computer. The smoke detector used here was the analogue light scattering type. The maximum values measurable by the smoke and the CO sensors were $25 \% / \mathrm{m}$ and $500 \mathrm{ppm}$, respectively.

Present study mainly deals with smoldering fires, since the early detection of smoldering fires is important particularly in the hotel rooms where the false alarms are strongly hated and the signals of smoke sensor include miscellaneous non-fire ones such as bathroom steam, cigarette smoke and dust in rooms under construction.

The multi-sensor fire detector developed by the author et al. ${ }^{3,4}$ requires the Fuzzy Expert System to judge fires or non-fires. The correlation between the smoke density and the concentration of carbon monoxide must fully be investigated to construct the recognition logic to judge fires or non-fires in air-conditioned rooms.

Experiments conducted here $(24$ cases including the 11 cases in Table 1$)$ to investigate the relationship between the flow behavior of fire gas and sensor output are as follows:

(1) The difference between warm and cool air-conditioning flows.

(2) The effect of air-conditioning flow with variation of the speed of air at the inlet.

(3) The effect of fire source location between in the center and in the corner of the room.

(4) The difference between smoke and gases by cotton cloth and polyurethane sheet which are popularly used in hotel rooms.

(5) The difference of fuel heating method between by conduction and radiation.

A sheet of cotton cloth, used for bedding, with dimensions of $40 \times 60 \mathrm{~cm}$ (about 29 grams) was folded into six layers and the eventual size of $20 \times 20 \mathrm{~cm}$. The cloth was heated on an electric heater of 600 watts (the heater was preheated for 200 seconds in advance to get reproducibility) as in the following two ways, since the former study ${ }^{\text {) }}$ indicated the dependency of the heating ways upon the smoke and gas generation.

${ }^{*}$ Heating way I (conductive heating) : the six layer cotton cloth was heated on a steel plate (20 X $20 \mathrm{~cm} \times 2 \mathrm{~mm}$ (thickness)) located just above the heater.

*Heating way II (radiative heating) : the six layer cotton cloth was heated on a coarse steel net located $5 \mathrm{~cm}$ above the heater.

A sheet of polyurethane (dimensions of $20 \times 20 \times 4 \mathrm{~cm}$ and 24 grams), used for bed or chair, was heated in the same ways (I and II) as in the case of cotton.

Details of the 11 cases in the present experiments are shown below.

TABLE 1

\begin{tabular}{llllc}
\hline & air-conditioning & fuel & smoke source location & heating \\
\hline CASE 1 & no & cotton & center & I \\
CASE 2 & no & cotton & center & II \\
CASE 3 & no & cotton & corner 3 & I \\
CASE 4 & no & polyurethane center & I \\
CASE 5 & no & polyurethane center & II \\
CASE 6 & cool & cotton & center & II \\
CASE 7 & warm & cotton & corner 3 & I \\
CASE 8 & warm & cotton & center & II \\
CASE 9 & cool & cotton & corner 3 & I \\
CASE 10 & cool & polyurethane corner 3 & I \\
CASE 11 & cool & polyurethane corner 3 & II \\
\hline
\end{tabular}




\section{Experimental Results}

\subsection{Measurements in the room without air-conditioning.}

First measured were the smoke density and carbon monoxide concentration in the calm room without air-conditioning flow. The temperature rise due to the smoldering fuel was almost negligible near the ceiling.

(1) The smoldering cotton placed in the center of the room.

The smoldering cotton fire source was placed in the center of the room. Figures 2-I-A and 2-II-A show the smoke and carbon monoxide gas as a function of time for Cases 1 and 2, respectively. Figures 2-I-B and 2-II-B show the correlation between the smoke and carbon monoxide. Generally the heating way II produced less carbon monoxide than the way I. However even by the way II where the smoke is dominant, the concentration of carbon monoxide is sufficiently detectable by the CO sensor (minimum level $=3 \mathrm{ppm}$ ) of the author et al. In either way it is clear that the carbon monoxide sensor together with the smoke sensor contributes to the early fire detection.

(2) The smoldering cotton placed in the comer.

The smoldering cotton fire source was placed in the corner (corner 3 shown in Figure 1 ) of the room. Figure 3-I-A shows the smoke and carbon monoxide gas for the Case 3. Figure 3-1-B shows the correlation between the smoke and carbon monoxide. The relationships between Figure 2-I-A and 3-I-A and the correlation curves between Figures 2-I-B and 3-I-B are quite similar to each other. The effect of fire location is minor upon the fire detection using the multi-sensor including carbon monoxide sensor.

(3) Smoke and carbon monoxide gas generated from the smoldering polyurethane.

Next measured were the smoke and carbon monoxide gas generated from the smoldering polyurethane sheet located in the center of the room. Figures 4-I-A and 4-II-A show the smoke and carbon monoxide gas for Cases 4 and 5, respectively. The amount of carbon monoxide produced by the smoldering polyurethane is less than that of cotton sheet in many cases, for example as seen in the comparison between Figures 2-I-A and 4-I-A. The concentration of carbon monoxide is however sufficiently detectable by the new $\mathrm{CO}$ sensor by the author et al.

\subsection{Measurement s in the cool or warm air-conditioned room}

The room was warmed or cooled for about 30 minutes by the air-conditioner in advance to the smoldering combustion of the fuel to get the experimental reproducibility.

(1) The smoldering cotton sheet placed in the center of the room.

The six layer smoldering cotton sheet heated by the way I was placed in the center of the room with either cool $(\mathrm{Vo}=1.0 \mathrm{~m} / \mathrm{s})$ or warm $(\mathrm{Vo}=2.5 \mathrm{~m} / \mathrm{s})$ air-conditioning. Figures $5-\mathrm{I}-\mathrm{A}$ and 5'-I-A show the smoke and carbon monoxide gas as a function of time for Cases 6 and 7 , respectively. And Figure 5-II-A is for the Case 8. Figures 5-I-B, 5'-I-B and 5-II-B show the correlation between the smoke and carbon monoxide.

The concentration of carbon monoxide and the smoke density become extremely low due to both the warm and cool air-conditionings. And the correlation curves become much broader compared with the cases of no air-conditioning. The smoke dilution causes the delay of fire detection by the traditional detectors, but the carbon monoxide sensor can assist the smoke sensor in the multi-sensor to detect fires earlier even if the signal levels to judge fires or non-fires are low.

In addition, it was observed that the smoldering combustion was slightly accelerated by the air-conditioning and produced more smoke. However the air-conditioning flow had much stronger effect in the view point of sensor signals, since the smoke and gas were diluted much more. 
FIGURE 2-I-A

Concentrations of carbon monoxide and smoke as a function of time.

(Case 1 : no air-con.)

FIGURE 2-I-B

Correlation between concentrations of carbon monoxide and smoke.

(Case 1)

FIGURE 2-II-A Concentrations of carbon monoxide and smoke as a function of time. (Case 2 : no air-con.)

FIGURE 2-II-B

Correlation between concentrations of carbon monoxide and smoke.

(Case 2)

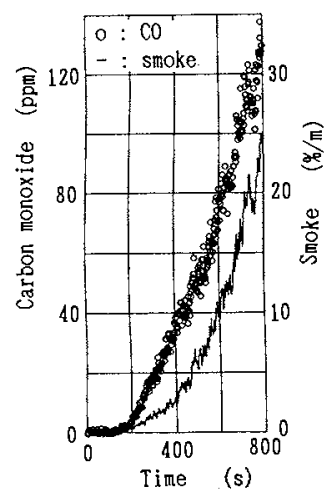

FIGURE 2-I-A (Case 1)

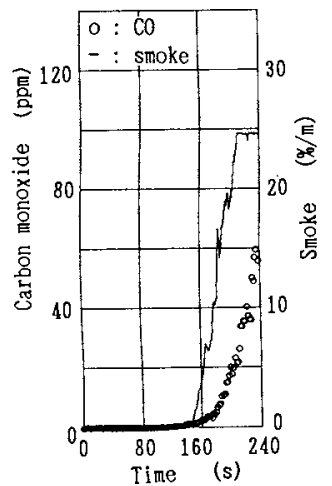

FIGURE 2-II-A (Case 2)

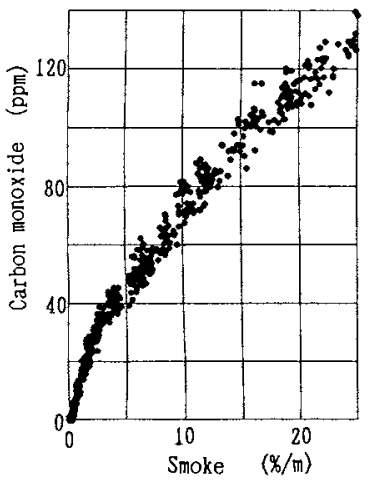

FIGURE 2-I-B (Case 1)

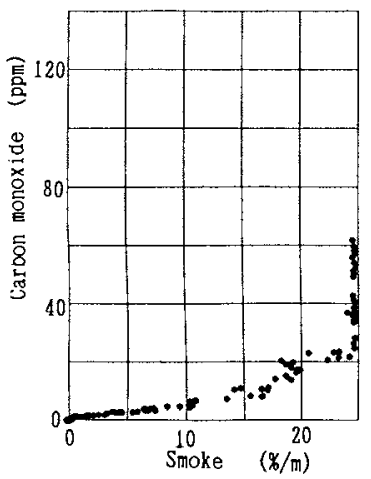

FIGURE 2-II-B (Case 2)

FIGURE 3-I-A

Concentrations of carbon monoxide and smoke as a function of time. (Case 3 : no air-con.)

\section{FIGURE 3-I-B}

Correlation between concentrations of carbon monoxide and smoke.

(Case 3)

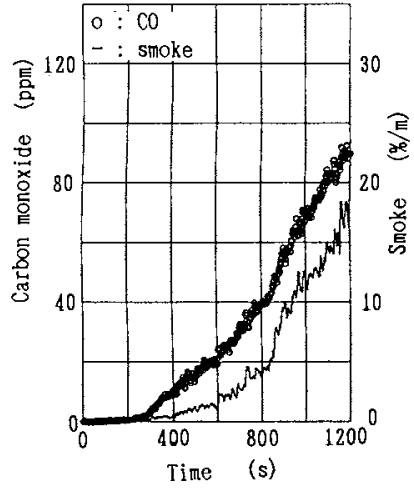

FIGURE 3-I-A (Case 3)

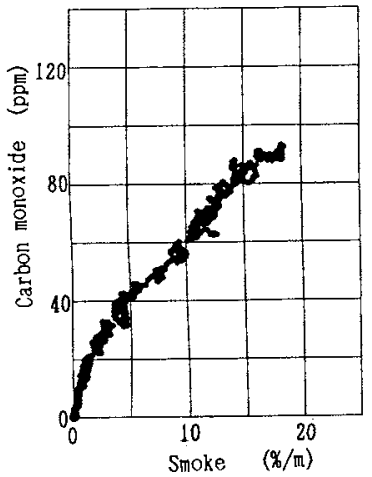

FIGURE 3-I-B (Case 3) 
FIGURE 4-I-A

Concentrations of carbon monoxide and smoke as a function of time. (Case 4 : no air-con.)

\section{FIGURE 4-II-A}

Concentrations of carbon monoxide and smoke as a function of time. (Case 5 : no air-con.)

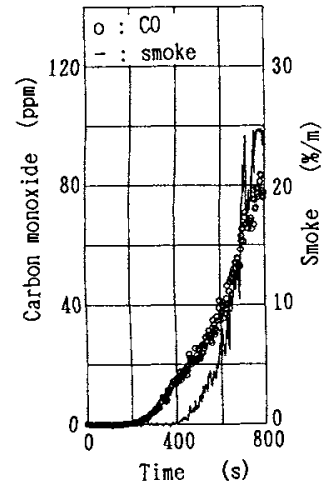

FIGURE 4-I-A (Case 4)

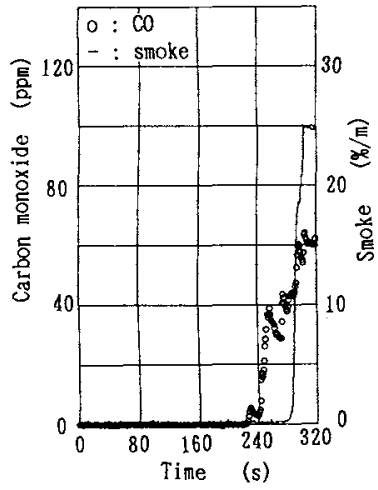

FIGURE 4-II-A (Case 5)

FIGURE 5-I-A

Concentrations of carbon monoxide and smoke as a function of time. (Case 6: cool air-con.)

FIGURE 5-I-B

Correlation between concentrations of carbon monoxide and smoke.

(Case 6)

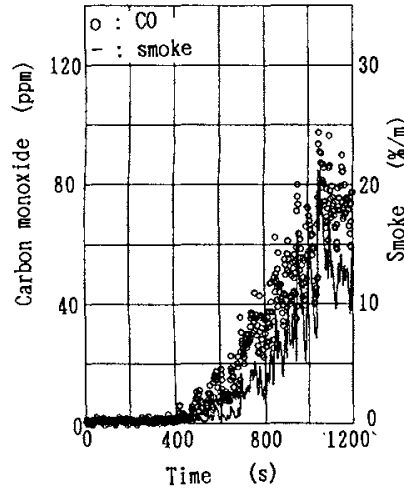

FIGURE 5-I-A (Case 6)

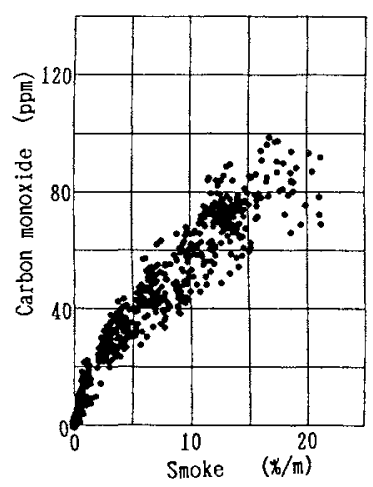

FIGURE 5-I-B (Case 6)

FIGURE 5'-I-A

Concentrations of carbon monoxide and smoke as a function of time. (Case 7 : warm air-con.)

\section{FIGURE 5'-I-B}

Correlation between concentrations of carbon monoxide and smoke.

(Case 7)

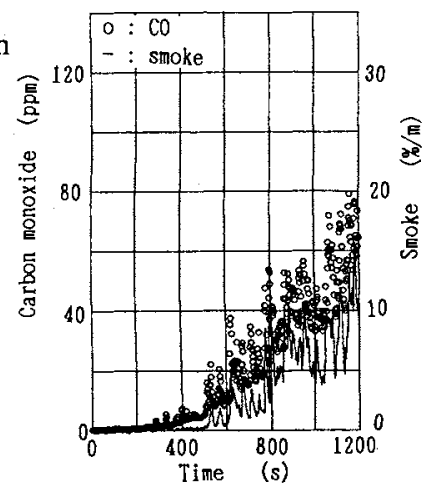

FIGURE 5'-I-A (Case 7)

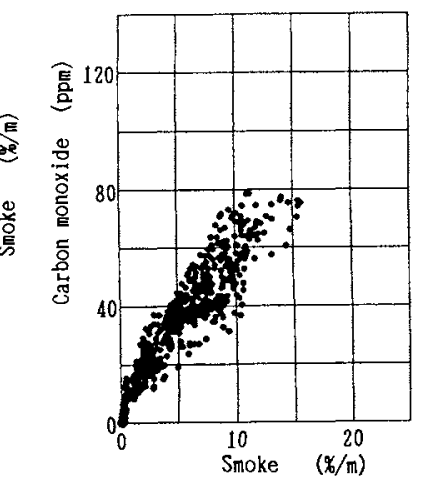

FIGURE 5'-I-B (Case 7) 
FIGURE 5-II-A

Concentrations of carbon monoxide and smoke as a function of time.

(Case 8 : warm air-con.)

FIGURE 5-II-B

Correlation between concentrations of carbon monoxide and smoke.

(Case 8)

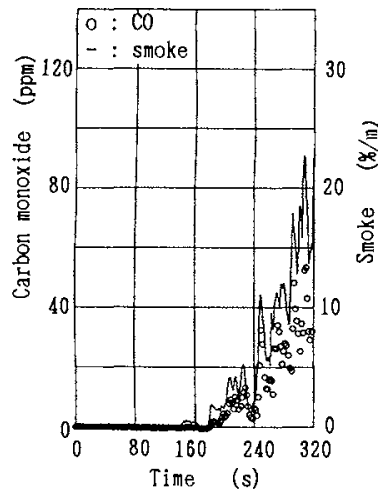

FIGURE 5-II-A (Case 8)

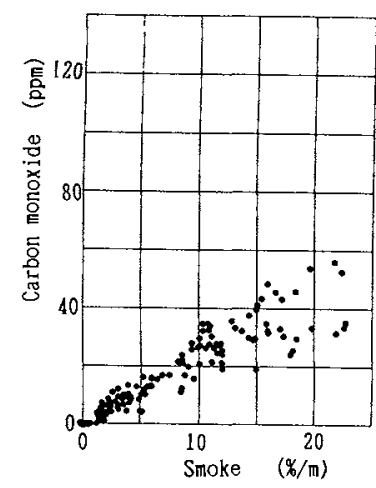

FIGURE 5-II-B (Case 8)

FIGURE 6-I-A

Concentrations of carbon monoxide and smoke as a function of time. (Case 9 : cool air-con.)

FIGURE 6-I-B Correlation between concentrations of carbon monoxide and smoke. (Case 9)

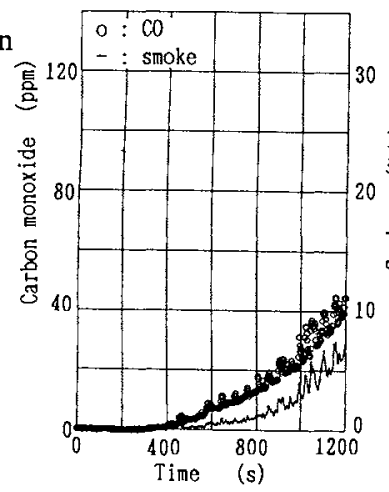

FIGURE 6-I-A (Case 9)

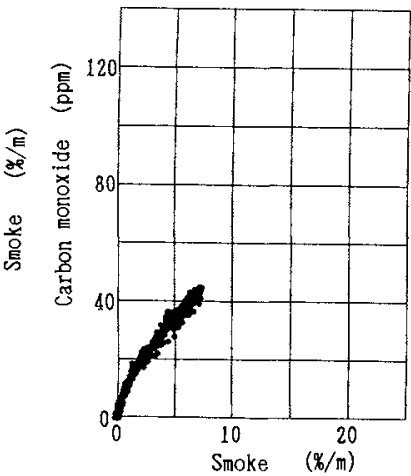

FIGURE 6-I-B (Case 9)

FIGURE 7-I-A

Concentrations of carbon monoxide and smoke as a function of time. (Case $10:$ cool air-con.)

FIGURE 7-II-A

Concentrations of carbon monoxide and smoke as a function of time. (Case 11 : cool air-con:)

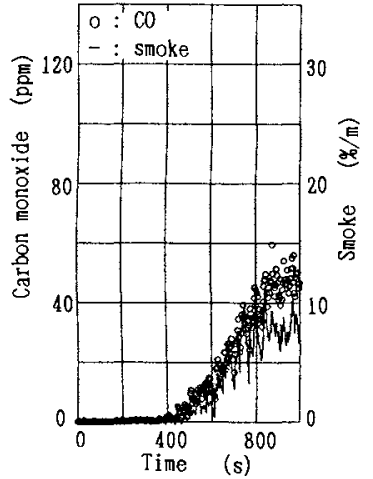

FIGURE 7-I-A (Case 10)

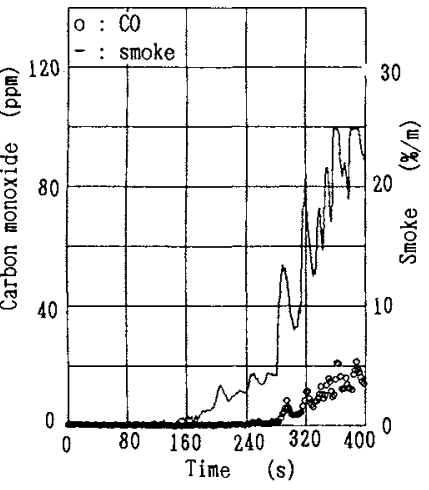

FIGURE 7-II-A (Case 11) 
(2) The smoldering cotton sheet placed in the corner of the room.

The cotton sheet was heated by the heating way I in the corner 3 of the room. Figure 6-I-A shows the smoke and carbon monoxide gas generated from smoldering cotton cloth in the case of $\mathrm{cool}(\mathrm{Vo}=2.5 \mathrm{~m} / \mathrm{s})$ air-conditioning (Case 9) and Figure 6-I-B shows the correlation between the smoke and carbon monoxide. In the other corners 1,2 and 4 of the room the smoke and carbon monoxide were affected similarly ${ }^{6}$ to the case of comer 3 for the air speed of $V_{0}=2.5 \mathrm{~m} / \mathrm{s}$. Thus it has been known that the signals of smoke detector in the case of comer fire source, too, are highly affected by the air-conditioning.

(3) The smoldering polyurethane sheet located in the center of the room.

Next measured were the smoke and carbon monoxide gas generated from the smoldering polyurethane sheet located in the center of the room. Figures 7-I-A and 7-II-A show the smoke and carbon monoxide gas in the case of cool $(\mathrm{Vo}=2.5 \mathrm{~m} / \mathrm{s})$ air-conditioning (Cases 10 and 11). The concentrations of the smoke and carbon monoxide gas are dependent on the air-conditioning flow and the fuel heating method, but the concentration of carbon monoxide is sufficiently detectable.

As seen in the experiments mentioned above, it has been found that the signals of smoke sensors are highly affected by the air-conditioning flow, but the concentration of carbon monoxide is sufficiently detectable. Therefore additional sensor signals such as carbon monoxide are helpful to detect fires earlier and reliably.

\subsection{Cigarette smoke, bath steam and dust in air-conditional flows}

The cigarette smoke and bath steam often cause false alarms in no air-conditioned rooms. It has been found by the author et al. ${ }^{3,4)}$ that the multi-sensors and Fuzzy Expert System are effective to reduce false alarms, but the false alarms of the system in the air-conditioned rooms have not been investigated yet.

Thus the smoke and carbon monoxide due to cigarettes were measured in the airconditioned room. Experiments showed that the signals of smoke and carbon monoxide were very low even when the smoking was done just below the detector. In addition it was observed that the bath steam quickly disappeared in the air-conditioning flow. However in some cases there appeared short period pulse signals for both cigarette smoke and bath steam. Moreover ash powder dusts generated just below the sensors in the air-conditioned room produced considerable signals for the smoke detector, but no signals appeared in the carbon monoxide sensor. These results indicate that the multi-sensor is effective to reduce false alarms even when the judgement of fires or non-fires is made at the lower level of sensor signals.

\section{NUMERICAL SIMULATTONS}

Numerical simulations were conducted in order to visually understand the flow pattern of both the fire gases and cigarette smoke (as a non-fire source) affected by the cool or warm air-conditional flow in the room.

\section{Numerical Methods}

The numerical code employed here is based on the finite difference method and called UNDFRI $^{5-10)}$ (the code extended from UNDSAFE ${ }^{11)}$ by the author). Three dimensional calculations were carried out to investigate the interactions between the air-conditional flow and the fire gas in the room with the same geometry as in the experiments shown in Figure 1. 
FIGURE 8 The pattern of cool air-conditioning flow in the vertical cross section $(85 \mathrm{~cm}$ apart from the wall) including the inlet opening.

$(\mathrm{V} 0=2.5 \mathrm{~m} / \mathrm{s}, \triangle \mathrm{T}=-6 \mathrm{~K})$
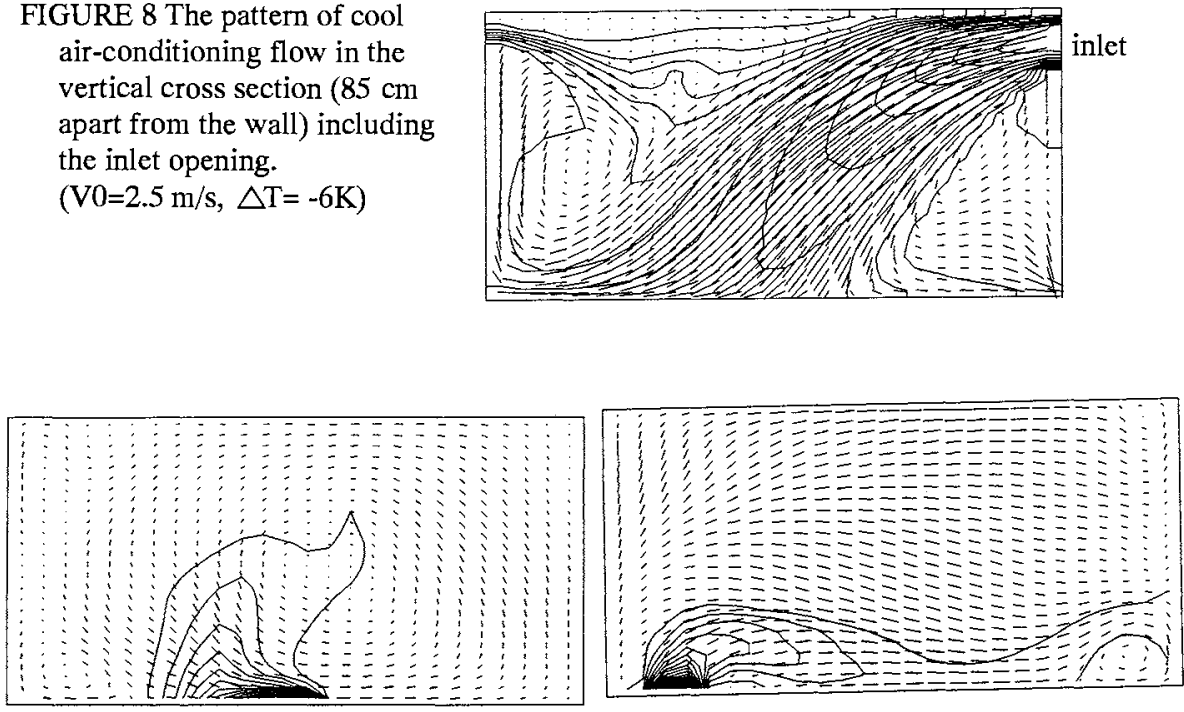

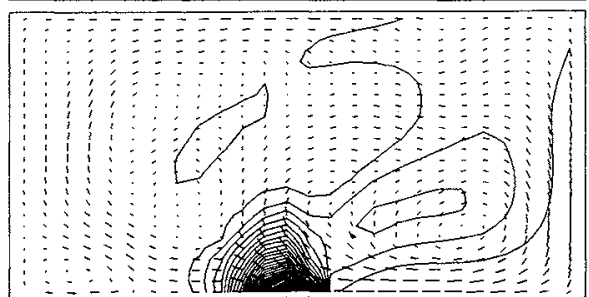

(Case A : Central fire source)

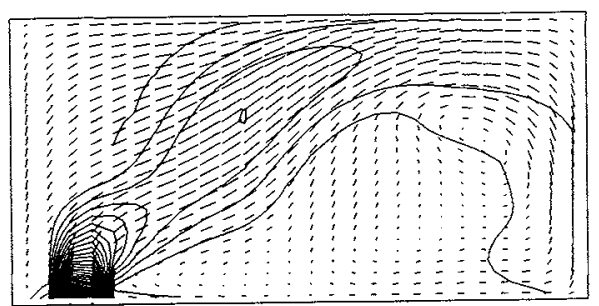

(Case B : Fire source at corner 3)

FIGURE 9 The time-dependent flow pattern FIGURE 10 The time-dependent flow pattern of the fire gas in the cool air-conditioning flow in the vertical central cross section. $(\mathrm{Vo}=0.8 \mathrm{~m} / \mathrm{s}, \triangle \mathrm{T}=-6 \mathrm{~K})$ of the fire gas in the cool air-conditioning flow in the vertical central cross section. $(\mathrm{Vo}=1.5 \mathrm{~m} / \mathrm{s}, \triangle \mathrm{T}=-6 \mathrm{~K})$

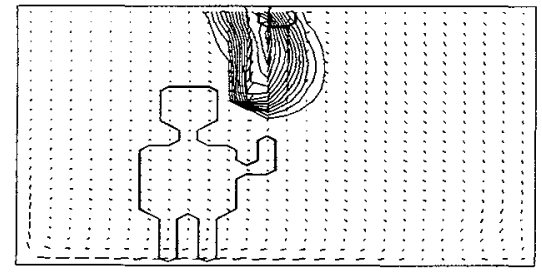

(Case $\mathrm{A}: \mathrm{Vo}=0.25 \mathrm{~m} / \mathrm{s}$ )

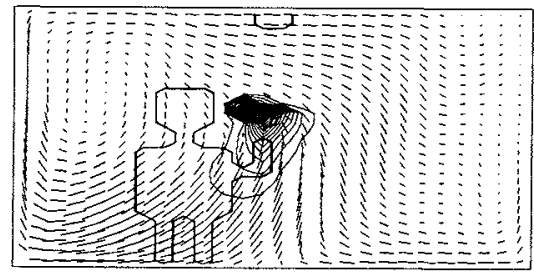

(Case B : $\mathrm{Vo}=2.0 \mathrm{~m} / \mathrm{s}$ )

FIGURE 11 The Flow pattern of cigarette smoke in the $\operatorname{cool}(\triangle T=-6 K)$ air-conditioning flow in the vertical cross section in the center. 
The room was divided into $28 \times 28 \times 28$ uniform grids, including solid boundary walls assumed adiabatic. The air-conditional flow ( $\mathrm{Vo}=0$ to $2.5 \mathrm{~m} / \mathrm{s})$ blown into the room was given at the boundary. The initial room temperature (To) was kept $20^{\circ} \mathrm{C}$. The warm $(+\triangle \mathrm{T})$ or cool $(-\triangle T)$ air was supplied where $\triangle T=6 \mathrm{~K}$ until the room temperature reached approximately constant. The heat strength (maximum value of $1 \mathrm{~kW}$ ) applied to the fire source was linearly increased with time. The smoke source was in the same area as the heat source and the generation rate was set at an arbitrary value. But the distribution of smoke concentration calculated by the species equation does not coincide with the temperature field in the air-conditining flow playing as the positive or negative heat source.

\section{Numerical Results of flow patterns of smoke in the room}

First examined were the flow patterns of warm or cool air-conditioning without any fire source in the room. Figure 8 shows the vertical cross sectional view of the $3-\mathrm{D}$ numerical result of the isothermal flow pattern in the $\operatorname{cool}\left(\mathrm{V}_{\mathrm{O}}=2.5 \mathrm{~m} / \mathrm{s}, \triangle \mathrm{T}=-6 \mathrm{~K}\right)$ air-conditioning. The cool air flow reaches the floor and turns along the opposite side walls. Although some other cases of warm and cool air-conditioning flow were examined varying the blowing speed from 0.25 to $2.0 \mathrm{~m} / \mathrm{s}$, the air flows in the roomwere stirred up considerably.

Next investigated were the time-dependent flow patterns of smoke placed in the airconditional flows as examined above. Two cases of the weak (Case A) and mild (Case B) cool air-conditining flows are shown in Figures 9 and 10. Figure 9 shows the cross sectional view, in the vertical center line, of the time-dependent flow pattern of the smoke in the cool air-conditioning flow $(\mathrm{Vo}=0.8 \mathrm{~m} / \mathrm{s})$. Figure 10 shows the cross sectional view, in the vertical plane near the wall at the corner 3 , of the smoke distribution in the cool air-conditioning flow $(\mathrm{Vo}=1.5 \mathrm{~m} / \mathrm{s})$. The smoke is highly varying with time and diluted. In the experiments, too, the smoke above the smoldering fire source was swaying and dispersing with time similarly to the numerical simulations. These figures are helpful to visually understand the fire gas flow in the air-conditional flow, in relation to the early fire detection.

\section{Numerical simulations of cigarette smoke around a fire detector}

Conducted were numerical simulations for the cigarette smoke ejected from a human mouth in the cool air blowing with the speed of either $\mathrm{Vo}_{0}=0.25$ (Case A) or $2.0 \mathrm{~m} / \mathrm{s}$ (Case B). Figure 11 shows the pattern of cigarette smoke in the weakly air-conditioned room (Case A). The smoke reaches the fire detector at the ceiling and a false alarm may happen. Figure 11 shows the flow pattern of the cigarette smoke in the comparatively strong cool air (Case B). The smoke is quickly dispersed by the cool air, where the signals of smoke or gas detector become below the detection level or produce only short period signals like pulse, similarly to the experiments conducted as above.

The warm air-conditioning showed the similar effect upon the smoke flow of cigarette. Thus it can visually be understood that there are comparatively less false alarms by cigarette smoke in the medium or much stronger air-conditional flow. Numerical simulations are helpful to understand the flow in rooms regarding the reliable fire detection. 


\section{DISCUSSION}

Some studies ${ }^{2)}$ have examined the extremely high-sensitive fire detectors to install in air-conditioned computer rooms, but dusts in those rooms may produce false alarms as long as single smoke sensor is used. And high-sensitive fire detectors must produce frequent false alarms in many kinds of ordinary rooms where miscellaneous non-fire sources are existent.

It was observed that the smoldering combustion was slightly accelerated by the airconditioning, but the dilution of smoke and fire gas due to the air-conditioning was much stronger in the view point of the signals of sensors.

Experiments showed that there were both cases where the smoke precedes to the carbon monoxide and the carbon monoxide is produced first. However in either way, the multisensor including the carbon monoxide sensor is effective in the early fire detection due to the mutual cooperation between both sensors even if one sensor signal is less than the alarm level.

The multi-sensor including carbon monoxide sensor (polymer film Nafion) developed by the author et al. ${ }^{3)}$ are based on the Fuzzy Expert System. To construct the System needed are the data base of signals of the smoke sensor and the carbon monoxide sensor in relation to the fires and non-fires in the air-conditioned rooms. Present experimental results and numerical simulations particularly in the space like hotel rooms have usefully showed the extent of dilution of the smoke and fire gases by the air-conditioning as functions of the fire location, the heating ways, the smoldering fuel, the warm or cool air-conditioning and the blowing speed.

The smoke sensor signal may exceed the detection level due to the dust in rooms, but the present multi-sensor fire detector never produces false alarms since the dust never includes the carbon monoxide. In addition the pulse short period signals due to the non-fire sources in the air-conditioned rooms are easily treated by the multi-sensor in cooperation with the carbon monoxide sensor and the smoke sensor.

The judgement of fires or non-fires in the air-conditioned rooms is made in lower sensor signal levels than the traditional ones, so multi-sensor fire detectors including the carbon monoxide sensor are highly effective to detect fires earlier and reliably in air-conditioned rooms.

Here made were no detection studies of flaming fires in the air-conditional flows, but they are now under investigation since the multi-sensor fire detector by the author et al. has a heat sensor. The carbon monoxide sensor can assist the heat sensor because the flaming fires produce the carbon monoxide gas more or less.

\section{CONCLUSIONS}

It has been found that the smoke and fire gases in rooms are highly diluted by the airconditioning, which leads to the reduced signals and therefore causes the delay or missing of fire detection by the traditional fire detector.

The smoldering combustion was slightly accelerated by the air-conditioning, but the dilution of smoke and fire gas due to the air-conditioning was much stronger in the view point of the signals of sensors.

There are both cases where the smoke precedes to the carbon monoxide and the carbon monoxide is produced first, but in either way, the multi-sensor including the carbon monoxide sensor is effective in the early fire detection by the mutual cooperation between both sensors.

The multi-sensor including carbon monoxide sensor based on the Fuzzy Expert System 
requires the data base of signals of the smoke sensor and carbon monoxide sensor in relation to the fires and non-fires in the air-conditioned rooms. Present experimental results and numerical simulations have usefully showed the extent of dilution of the smoke and fire gases by the air-conditioning as functions of the fire location, the heating ways, the smoldering fuel, the warm or cool air-conditioning and the blowing speed.

\section{REFERENCES}

1. Luck, H.O. : "Dedicated Detection Algorithms for Automatic Fire Detection", Fire Safety Science - Proceedings of the Third International Symposium, IAFSS, p.135, 1992

2. Johnson, P.F.: "Very Early Smoke Detection for Computer Telecommunications Industries", Fire Safety Joumal, Vol.14, p.13, 1988

3. Satoh, K., A.Takemoto and D.Kouzeki : "Study of Intelligent Fire Detection System using Multi-Sensor and Fuzzy Expert System", Technical Report of Fire Research Institute, No.26 \& 28, Fire Research Institute of Japan, 1991

4. Satoh, K. and S. Kusanagi: "Study of Intelligent Fire Detection System Causing Less False Alarms", Japan Association for Fire Science and Engineering, Vol.43, No.3, p.19, 1993

5. Satoh, K. : "Modeling of Fire Detection in Air-Conditioned Rooms", Proceedings of 12th Joint Panel Meeting of the UJNR , BRI \& FRI, p.102, 1992

6. Satoh, K. : "The Fire Detection in Air-Conditioned Rooms (in Japanese)", Proceedings of Japanese Safety Engineering Conference, p.11, 1989

7. Satoh, K. and D.D. Evance : "Comparative Predictions of Fire Generated Ceiling-Jet Gas Temperatures in an Enclosure using both a 3-Layer Zone Model and a Field Model", Proceedings of 20th Technical Meeting of Eastern Section Combustion Institute, NBS, 105-1, 1987

8. Satoh, K. : "A Numerical Study of Ceiling Jets Based on 'T' Pattern Flames", Fire Safety Science - Proceedings of the Second International Symposium, IAFSS, p.159, 1989

9. Satoh, K. and K. Kuwahara: "A Numerical Study of Window-to-Window Propagation of High-Rise Building Fires", Fire Safety Science - Proceedings of the Third International Symposium, IAFSS, p.355, 1991

10. Satoh, K.: "A Numerical Study of Dynamic Fire Behavior", JSME International Journal, Vol.31, No.3, p.402, 1988

11. Yang, K.T., J.R.Lloyd, A.M. Kanury and K. Satoh : "Modeling of Turbulent Buoyant Flow in Aircraft Fires", Combustion Science and Technology, Vol.39, p.107, 1984 